\title{
A história nas histórias
}

\section{Maria Clementina Pereira Cunba}

Davis, Natalie Zemon. Histórias de perdão e seus narradores na França do século XVI. São Paulo: Companhia das Letras, 2001. 315 p.

Se historiadores cultivassem a mania norte-americana de escolher os "dez mais" para estabelecer o ranking de seu próprio ofício, seguramente Natalie Zemon Davis figuraria em todas as listas em posição de destaque. Nas últimas duas décadas, excepcionalmente férteis nesta área, seus trabalhos têm tido uma repercussão notável e inspirado profissionais do mundo inteiro por sua ousadia, capacidade de inovar e buscar formas alternativas de pesquisa, interpretação e exposição de resultados. Esta posição consolidou-se desde o aparecimento da obra-prima $O$ retorno de Martin Guerre. Publicado originalmente em 1982 e traduzido para o português em 1987, o livro enriqueceu uma intensa polêmica entre especialistas, abrindo o campo sobre o qual a autora voltou a debruçar-se em Histó- rias de perdão e seus narradores na França do século XVI, de 1987, que a Companhia das Letras acaba de traduzir e publicar. Impossível, por isto, discutir este livro sem remeter ao anterior e ao seu impacto na historiografia contemporânea.

Com a história de Martin, Bertrande, do simpático impostor Pansette e outros personagens da pequena aldeia de Artigat, nos Pireneus, narrada com a estrutura e a graça de um romance (e antes, de um filme - "laboratório" que colocou para a autora novas questões relativas à especificidade do discurso historiográfico), Natalie Davis se colocava entre aqueles historiadores que afirmavam a possibilidade de conhecer algo da experiência de gente de carne e osso perdida nas brumas do passado. Com Martin Guerre e seus companheiros de aventura ela alcançou este mundo desaparecido sem recorrer a grandes categorias explicativas, abstratas e finalistas: são as vidas de homens e mulheres comuns que aparecem naquelas 
páginas, compreendidas através dos significados de um episódio de grande apelo literário. Ela enfrentava assim de modo original os impasses criados pela crise dos paradigmas que, de diferentes maneiras, paralisava alguns historiadores e estimulava outros à busca de novas respostas. A micro-história, na Itália, assim como algumas obras importantes $\mathrm{da}$ chamada "Nova História" cultural francesa e parte da historiografia norte-americana podem ser apontadas como produtos deste mesmo impulso.

O mais impressionante, no caso deste livro, é que não houve chance de recorrer a uma documentação "direta". Seu resultado, assim, ampliou e legitimou como procedimento historiográfico o uso da conjectura, das evidências paralelas, do cruzamento de informações, da especulação controlada e amparada por uma sólida pesquisa que permita inserir os indivíduos em seu contexto, explicando a um só tempo uns e outros. No caso, o relato do jurista Jean de Coras, em seu Arrest Memorable foi cotejado com uma ampla gama de fontes manejadas com admirável habilidade. Obras anteriores que marcaram profundamente a historiografia do século XX têm esta mesma marca: E. P. Thompson, por exemplo, em Senhores e caçadores, de 1975, enfrentou a mesma ausência de documentação específica sobre a Lei Negra - produzindo uma interpretação original a partir de uma investigação impressionante em fontes paralelas, suficiente para sustentar conclusões que incomodaram seriamente tanto os especialistas presos a velhos modelos teóricos ou a procedimentos convencionais de análise quanto os intérpretes que não conseguiam ver na história senão a "imaginação" dos historiadores. Thompson foi classificado por Hayden White como um vulgar "empirista" em seu esforço em desvendar novos aspectos da sociedade inglesa no século XVIII em $A$ formação da classe operária inglesa — crítica dirigida também a toda a sua obra, inclusive a interpretação dos significados da lei como um campo de embates e produção de direitos. O notável caso de Menocchio, ressuscitado em livro por Ginzburg em 1976, deixou ecos semelhantes - e outros exemplos poderiam ser mencionados para recuperar um pouco da atmosfera intelectual na qual Natalie Davis trouxe à luz estas Histórias de perdão, tomando-as como objeto de um exercício que nos traz 
de volta ao debate, nunca esgotado, sobre a questão. Em meio a esta atmosfera tão rica quanto conturbada, Natalie Davis forjou sua própria maneira de lidar com a história, imprimindo-lhe definitivamente sua marca. Basta lembrar que, um ano após a publicação das Histórias de perdão, seus pares ainda discutiam as implicações de sua narrativa sobre a história de Martin Guerre como se pode ver no seu diálogo de 1988 com Robert Finlay na American Historical Review ou nos comentários posteriores de Ginzburg. Não se deve, assim, dissociar um trabalho do outro sob pena de perdermos seus melhores desdobramentos e significados.

Com Martin Guerre, que veio à luz quase uma década depois do livro de Thompson e quatro anos após os "trópicos" de Hayden White, a autora trouxe para o centro do seu trabalho a celeuma sobre a positividade da história, as fronteiras entre fato e ficção ou entre literatura e história, que ganhara corpo no final dos anos 1970 e início dos 80. Fêlo com ousadia e provocou um amplo campo de objeções. A história de Martin Guerre é uma “invenção” para usar o vocabulário do teórico norte-americano Hayden White - mas produzida através de uma escuta atenta de vozes do passado. Diante dele, historiadores mais convencionais protestaram contra a extrapolação, a conjectura e, mais ainda, contra a construção ficcional como parte do trabalho científico. Do outro lado, aqueles que julgavam que vozes do passado não se podiam fazer ouvir em velhos papéis (e que, portanto, julgavam que ao historiador apenas interessava seu próprio processo de "invenção" ou restringiam as possibilidades cognitivas da história à desconstrução de textos), escarneceram de sua tentativa de atingir, como Thompson ou Ginzburg, a experiência de homens "reais". Em outras palavras, discutia-se o "princípio de realidade" da história em seu jogo entre verdades e possibilidades. Se a insistência de Natalie Davis em buscar a experiência dos camponeses e aldeões na França moderna foi capaz de encantar a todos pela maestria do texto, a redução na escala da análise e o modo de ver e narrar desgostaram aqueles que preferiam apostar em categorias gerais desgastadas pelo (mau) uso. Incomodou igualmente os que questionavam, em uma perspectiva próxima às variantes de uma historiografia pós-moderna, a possibilidade 
de recuperar valores e modos de vida reeditando, de certa forma, a polêmica que cercou, com referências um pouco diversas, o massacre de gatos de Darnton - publicado pouco depois do Martin Guerre que envolveu, em 1985, nomes como os de Roger Chartier e Dominick LaCapra: o que podemos acessar da experiência do passado a partir destes relatos? Em que medida textos de juristas, literatos, advogados e outros agentes, cifrados e conformados pelas etiquetas narrativas da retórica ou pelos seus próprios objetivos institucionais, podem ser tomados como vestígios de modos de vida, da cultura popular e seus significados - ou em que medida se deve tomá-los como representações ou discursos que falam apenas de seus próprios autores? Até que ponto a retórica, os cânones discursivos ou os enunciados da cultura letrada que revestem textos empoeirados dos arquivos permitem acesso a valores e comportamentos humanos cujos significados teriam sido irremediavelmente sepultados com seus praticantes? A história, entendida como a interpretação de acontecimentos do passado, seria ainda um exercício intelectual e político legítimo?
Estas Histórias de perdão mantêm, assim, estreitas ligações com um debate que envolvia diferentes concepções de história e posições opostas a respeito de sua legitimidade como saber sobre o passado. Talvez estas críticas ao seu livro de 1982 a tenham levado rapidamente a este novo exercício a partir de um conjunto de fontes já parcialmente percorrido em sua incursão pela história de Martin Guerre. O universo das cartas de remissão foi o ponto de partida para uma retomada destas interrogações que giram igualmente em torno do ofício do historiador e da história cultural da França no século XVI. O título originalmente escolhido para o volume, "Ficção nos arquivos", secundado pelo subtítulo "histórias de perdão e seus narradores na França do século XVI" talvez tenha parecido um tanto tedioso para os editores que, em boa hora, traduziram para o português o volume publicado nos Estados Unidos. Seu aparente paradoxo, entretanto, aponta inequivocamente para esta intenção.

Não à toa, Natalie Davis abre seu livro relembrando velhas lições de história a respeito dos "fatos reais" que aprendeu em seus anos de estudante. Evoca assim passagens conhe- 
cidas de Hayden White em seu Trópicos do discurso: "se reconhecêssemos a existência de um elemento fictício em toda narrativa histórica, haveríamos de encontrar na própria teoria da linguagem e da narrativa a base para a representação daquilo em que consiste a historiografia, representação mais sutil que aquela que simplesmente exorta o estudante a ir adiante e a 'descobrir os fatos' lançando-os por escrito de modo a relatar 'o que realmente aconteceu". A rápida menção a este autor — referência fundamental para um dos lados neste debate sobre os significados da história - logo nas primeiras páginas de um livro dedicado a discutir fontes e seus usos, explicita o campo no qual sutilmente Natalie Davis se coloca. Dir-se-ia que o livro, à primeira vista despretensioso em seus objetivos, tem a dimensão de um acerto de contas com a formação acadêmica e com os descaminhos e fracionamento da disciplina histórica. Por isso ele trata fundamentalmente dos mecanismos de construção textual, discutindo para bons entendedores - como se situar diante destes e outros tipos de testemunho do passado. $\mathrm{O}$ esforço equivale a exibir os alicerces, andaimes e estruturas do seu próprio tra- balho, desnudando formas de aproximação, leitura e interpretação de um conjunto de fontes que, ao mesmo tempo, relatam e reelaboram ficcionalmente histórias verídicas de criminosos em busca do perdão.

O primeiro momento do exercício corresponde ao propósito de contextualizar os documentos que tem em mãos. No primeiro capítulo, intitulado "A época em que se contavam histórias”, Natalie Davis busca inserir cuidadosamente as cartas de perdão em uma rede de textos de diferentes naturezas, para estabelecer seu significado político na França do século XVI. Assim, desvenda para os leitores as funções, os mecanismos de produção discursiva, os objetivos pretendidos com estes relatos destinados a convencer, comover e obter perdão - bem como as referências literárias e culturais que os sustentam. No segundo capítulo, a análise assume uma outra direção: em "A raiva e a legítima defesa" é discutida basicamente a maneira pela qual estas narrativas se estruturam na tentativa de obter remissão de penas. Atendendo ao objetivo de justificar moralmente a violência em torno de valores socialmente compartilhados, capazes de abrir caminho para o perdão real, 
estes textos — avaliados em seu conjunto - revelam temas, estratégias narrativas, princípios organizadores comuns e negociados entre condenados e homens da lei, que giram em torno das formas aceitáveis de justificação da violência e da culpa.

Finalmente no terceiro e último capítulo, que intitulou "O derramamento de sangue e a voz da mulher", Natalie Davis assume uma posição no debate para estabelecer de modo inequívoco a relação dos documentos com a experiência social dos sujeitos. Já não se trata mais de analisar a textualidade - o discurso em seus critérios literários ou em suas intenções ou funções mas de aplicar-lhes os filtros com os quais os historiadores buscam clarear a audição para escutar vozes do passado, de sujeitos "reais" que nos contam sobre si e sobre o mundo em que viveram. A escolha da autora recai justamente sobre as mulheres - para as quais a obtenção do perdão era mais difícil, resultando em cartas de remissão mais elaboradas e complexas que, ao mesmo tempo em que ocultam suas razões e sentimentos, revelam tanto mais de sua experiência histórica. É inevitável ouvir aí murmurar Bertrande de Rols junto a estas companheiras de infortúnio, embora suas histórias tenham tramas e desfechos diferentes. Todas elas, de certo modo, antecipam as vozes de outras mulheres, seres das margens de que vai se ocupar no livro seguinte com a habilidade de sempre.

Estamos a milhas de distância, ao fim do livro, das inquietações pós-modernas e do velho zelo positivista. Resta ao leitor a clara sensação de uma "ressonância mais ampla” que, segundo ela, devemos encontrar entre estas curiosas narrativas e nosso complicado mundo contemporâneo. Por que, afinal, achamos engraçados estes velhos relatos? - pergunta-nos no final do percurso. Tudo a ver com a maneira pela qual entendemos o significado da história e nos apropriamos das dimensões sempre renovadas do tempo. 